\title{
SIMPLICIDADE DE DEUS E RACIONALIDADE DO MUNDO
}

\author{
Ethel Rocha* \\ ethel.rocha55gmail.com
}

RESUMO Neste artigo, pretendo examinar a tese cartesiana da livre criação das verdades eternas a partir da conjugação dos atributos divinos que, segundo Descartes, são conhecidos por nós e sua tese de que, entre as verdades eternas livremente criadas por Deus, estão incluidos os princípios lógicos. A partir desse exame, concluo que, até onde o intelecto finito do homem pode conceber, a tese cartesiana da livre criação das verdades eternas envolve ao menos as seguintes teses: a) Deus, por ser infinito e puro pensamento em ato, estabelece necessariamente em si todas as essências e verdades, incluindo essências e verdades que para o intelecto finito parecem impossíveis, já que lhe aparecem como contraditórias; b) ao estabelecer as essências e verdades, Deus instancia algumas (e assim as cria) como conteúdos de ideias inatas nas mentes finitas, que são criadas com estrutura lógica; c) ao estabelecer as essências e verdades, Deus instancia no mundo atual ao menos algumas das essências e verdades não contraditórias instanciadas nas mentes finitas; $e d$ ) embora a mente humana finita não as possa conceber clara e distintamente, é certo que Deus instancia no mundo atual ao menos algumas das essências e verdades que aparecem como contraditórias, isto é, instancia no mundo atual a menos algumas das essências e verdades que para a mente finita aparecem como impossiveis por serem por ela inconcebiveis, o que é confirmado por ao menos dois casos mencionados por Descartes.

Palavras-chave Deus, racionalidade, verdades eternas.

* Professora Associada, Departamento de Filosofia da UFRJ. O artigo é parte de pesquisa financiada pelo CNPq/Pronex. Artigo recebido em 22/01/2013 e aprovado em 15/04/2013. 
ABSTRACT In this article I intend to examine the Cartesian view on the free creation of the eternal truths considering the conjunction of the divine attributes, which according to the Cartesian thesis, are known to us and his thesis that logical principles are among the eternal truths freely created by God. From this examination I conclude that, as far as the finite intellect of man can conceive, the Cartesian view of the free creation of the eternal truths involves at least the following theses: a) being pure and infinite thinking in action, God necessarily sets in himself all the form of essence and truth, including all essence and truth that for, the finite intellect, seem impossible since they may appear to him as contradictory; b) while establishing all essence and truth, God instantiates some of them (and thus creates some of them) as contents of innate ideas in finite minds, which are created with a logical structure; c) while establishing all essence and truth God instantiates in the actual world at least some of the non-contradictory essences which are instantiated in the finite mind; and d) although the finite human mind cannot conceive it clearly and distinctly, it is certain that God instantiates in the actual world at least some of essence and truth that seem to be contradictory for the human mind, that is, God instantiates at least some of the essences and truths which appear to the finite mind as impossible since inconceivable, which is confirmed by at least two cases mentioned by Descartes.

Keywords God, rationality, eternal truth.

\section{Simplicidade de Deus e racionalidade do mundo}

É sabido que Descartes sustenta a tese forte de que as verdades eternas são livremente criadas por Deus. A tese não é apenas a de que tudo (inclusive as verdades eternas) depende de Deus, mas que tudo (inclusive as verdades eternas) depende da livre vontade de Deus, de tal modo que Deus poderia ter criado as coisas diferentemente de como as criou. Essa tese não aparece em nenhum livro publicado de Descartes, mas entre 1630 e 1649 (um ano antes de sua morte) está presente em sua correspondência (em 8 cartas), em suas respostas a duas das objeções feitas às "Meditações Metafísicas" e em "Conversação com Burman". Nesses textos, Descartes parece sugerir que a tese da livre criação das verdades eternas segue-se da tese tradicional de que a infinitude dos poderes de Deus é incompreensível. Isso fica claro, por exemplo, em carta a Mesland ${ }^{1}$ onde Descartes afirma: 
Passo agora à dificuldade de se conceber como Deus poderia agir livremente se tivesse feito com que fosse falso que os três ângulos de um triângulo fossem iguais a dois ângulos retos, ou em geral que contraditórios não pudessem ser verdadeiros ao mesmo tempo. É fácil dissipar essa dificuldade [...] considerando que o poder de Deus não pode ter limites, e que nossa mente é finita [...]. (AT IV, p. 118) ${ }^{2}$

Entretanto, apesar da incompreensibilidade acerca da infinitude dos poderes de Deus, Descartes sustenta a possibilidade de uma teologia especulativa na medida em que sustenta que podemos conhecer ao menos alguns atributos de Deus, como afirma em carta a Mersenne: "Mas há muitas coisas realmente em Deus, ou relativas a Deus, que somos capazes de alcançar com nossas mentes e expressar em palavras - na verdade mais do que no caso de qualquer outra coisa. E, portanto, nesse sentido, podemos conhecer Deus e falar muitas coisas sobre ele" (AT II, p. 284). Entre o que podemos falar sobre Deus consta sua onisciência, sua onipotência, sua simplicidade, sua univocidade, que ele é imaterial e que é ato puro: ${ }^{4}$ sabemos que Deus é perfeito e que, entre outras coisas, é puro pensamento de tudo, é uno e simples e, portanto, cria tudo que pensa. Neste artigo, pretendo examinar a tese cartesiana da livre criação das verdades eternas a partir da conjugação dos atributos divinos conhecidos por nós, tendo como pano de fundo a tese de que, entre as verdades eternas livremente criadas por Deus, estão incluídos os princípios lógicos. A partir desse exame, concluo que, até onde o intelecto finito do homem pode conceber, a tese cartesiana da livre criação das verdades eternas envolve ao menos as seguintes teses: a) Deus, por ser infinito e puro pensamento em ato, estabelece necessariamente em si todas as essências e verdades, incluindo essências e verdades que para o intelecto finito parecem impossíveis, já que lhe aparecem como contraditórias; b) Deus, ao estabelecer as essências e verdades, instancia algumas (e assim as cria) como conteúdos de ideias inatas nas mentes finitas que são criadas com estrutura lógica; c) Deus, ao estabelecer as essências e verdades, instancia no mundo atual ao menos algumas das essências e verdades não contraditórias instanciadas nas mentes finitas; e d) que, além disso, embora a mente humana finita não as possa conceber clara e distintamente, Deus instancia no mundo atual ao menos algumas das essências e verdades contraditórias, isto é, instancia ao menos algumas das essências e verdades que para a mente finita aparecem

2 As citações da obra de Descartes serão acompanhadas no texto da notação da edição de Adan \& Tannery (AT), seguida do número do volume e do número da página nessa edição.

3 Carta de 21 de janeiro de 1641.

4 M. Wilson (1978), em oposição a A. B. Gibson e H. Frankfurt afirma que a tese da livre criação das verdades eternas é a tese mais básica da qual depreende a simplicidade e univocidade de Deus (p. 122 e nota 21). 
como impossíveis por serem por ela inconcebíveis. Assim, como veremos, o exame da tese cartesiana da livre criação das verdades eternas mostrará que é necessário admitir que, embora esta tese não implique a tese forte da criação necessária de um mundo atual contraditório e, portanto, sem sentido aos olhos da mente finita, implica, entretanto, a tese igualmente forte de que Deus necessariamente cria essências e verdades que para a mente finita aparecem como impossíveis já que contraditórias; na esteira desse exame, será afirmado ainda que, dada a ontologia cartesiana, é necessário admitir que as essências e verdades criadas, por incluírem essências e verdades que são inconcebíveis pela mente finita, são todas criadas em Deus e que este, ao criá-las, instancia algumas nas mentes finitas criadas, que são estruturadas segundo princípios lógicos, e instancia algumas (ou todas) no mundo atual. Com recurso a dois exemplos, a saber, as teses da união corpo e alma e da liberdade humana consideradas no contexto da tese dualista e da tese da preordenação divina respectivamente, indicaremos que Descartes não só admite que no mundo atual há essências ou verdades que aparecem ao intelecto humano como contraditórias e que são, portanto, inconcebíveis por esse intelecto, mas também que, ao introduzir a discussão da compatibilidade dessas teses, deixa claro que a experiência humana, de alguma maneira, tem acesso ao menos a algumas dessas essências e verdades que ao intelecto humano aparecem como contraditórias. $^{5}$

O paradigma de verdades eternas, indicado por Descartes em diferentes textos, são as verdades matemáticas. Descartes inclui, entretanto, na lista de verdades eternas pelo menos os princípios lógicos, além de princípios metafísicos, físicos e morais. Que os princípios lógicos estão na lista das coisas criadas livremente por Deus é manifesto em diversas passagens, como por exemplo, nos "Princípios", ${ }^{6}$ quando Descartes diz: “[...] esta proposição

5 Essa leitura da tese cartesiana da livre criação das verdades eternas se opõe à interpretação defendida por H. Ishiguro (1986) e retomada por C. Normore (1991). Segundo Ishiguro, a tese cartesiana da livre criação das verdades eternas implica que Deus teria o poder de tornar falso o que é uma verdade necessária, mas não o de tornar verdadeiro o que é impossível (segundo o intelecto finito) de ser verdadeiro. Isto é, a tese cartesiana de que uma verdade necessária não é necessariamente necessária não implica que Deus tenha o poder de tornar verdadeira uma contradição. Neste artigo, pretendo mostrar que, embora de fato o poder de criar contradições não esteja implicado na tese de que Deus poderia não ter criado as verdades que criou, o poder (na verdade, como veremos, a necessidade) de criar contraditórios está implicado na conjunção da tese da livre criação das verdades eternas com o que é afirmado conhecermos acerca da natureza de Deus. Hishiguro defende essa sua leitura afirmando que Descartes nunca teria dito que Deus poderia ter criado contraditórios o que, entretanto, não parece ser o caso, a julgar pelo que Descartes diz em cartas a More, a Mersenne e a Mesland, citadas adiante. (Vejam-se referências nas notas $5,6$ e 7$)$.

6 As citações de passagens dos "Princípios da Filosofia" serão extraídas da tradução coordenada por Guido A. de Almeida (Editora UFRJ, 2002). "Princípios” I, p. 49. 
a partir do nada nada vem é considerada [...] como uma certa verdade eterna [...] Desse gênero são: é impossivel que o mesmo seja e não seja ao mesmo tempo [...] e inúmeras outras" (AT VIIIA, p. 24, grifos do original). Além de criados, os princípios lógicos são criados como estrutura do intelecto finito fica claro também em várias passagens, por exemplo, nessa mesma passagem dos "Princípios", onde ele afirma que a proposição a partir do nada nada vem a ser, e outras do mesmo gênero (como é impossível que o mesmo seja e não seja ao mesmo tempo), são consideradas não como alguma coisa existente, tampouco como um modo da coisa existente, "mas como uma certa verdade eterna que tem sua sede em nossa mente [...]" (ATVIIIA, p. 23, grifo meu), ou em carta a Arnauld, ${ }^{7}$ onde Descartes diz: "[...] eu nem mesmo ousaria dizer que Deus não pode fazer uma montanha sem vale, ou que um mais dois não seja três. Eu apenas digo que ele me dotou de um mente de tal modo que não posso conceber uma montanha sem um vale, ou a soma de um mais dois sem ser três, e que essas coisas envolvem uma contradição em minha concepção" (AT V, p. 224, ênfase acrescentada). Mais ainda, essa estrutura lógica da mente finita é, segundo Descartes, o que torna essa mente finita, limitada. Isso fica claro na Quarta Meditação, onde Descartes afirma que a mente finita é dotada de duas faculdades, a saber, o entendimento que é finito e passivo e é responsável por conceber ideias e a vontade, infinita e ativa, responsável por toda ação, inclusive qualquer ato mental que se acrescente às representações do entendimento como quando se quer algo, se afirma algo, se duvida de algo etc. A infinitude da vontade é o que torna a mente finita semelhante a Deus e a finitude do entendimento é o que a limita. ${ }^{8}$

Logo em um primeiro momento parece razoável afirmar, portanto, que se para Descartes Deus criou os princípios lógicos como estrutura do intelecto finito, então é pelo menos possível que no ato da criação Deus não esteja, ele próprio, submetido aos princípios lógicos que limitam a mente finita, isto é, é possível que Deus não esteja sujeito a esses princípios que são criados como estrutura do intelecto finito. Mais ainda, sendo os princípios lógicos criados como estrutura da mente finita, é razoável afirmar também que é possível que o conceito mesmo de contraditoriedade esteja relacionado apenas à mente humana. $\mathrm{O}$ que à mente finita aparece como contraditório e, por isso mesmo, impossível de existir, parece ser uma limitação da mente finita que não necessariamente corresponde ao que de fato, isto é, do ponto de vista do criador, é real. Isso é o que Descartes parece afirmar em inúmeras passagens, 
por exemplo, em carta a More, ${ }^{9}$ onde diz: “Ouso afirmar que Deus pode fazer tudo o que percebo ser possível, mas não sou tão ousado a ponto de afirmar o contrário, a saber, que ele não possa fazer o que entra em conflito com minha concepção das coisas - apenas digo que envolve uma contradição" (AT V, p. 276); ou em carta a Mersenne, ${ }^{10}$ ao afirmar: "Podemos afirmar de um modo geral que Deus pode fazer tudo o que está no escopo de nossa percepção, mas não que ele não possa fazer o que está além de nossa percepção [...]" (AT I, p. 146); ou ainda, em carta a Mesland, ${ }^{11}$ quando diz: "[...] Deus não pode ter sido determinado a tornar verdadeiro que contraditórios não possam existir conjuntamente e, portanto, [...] ele poderia ter feito o oposto" (AT IV, p. 118).

A tese de que é possível que o intelecto finito não possa perceber clara e distintamente tudo o que Deus cria parece ser explicada por uma tese mais ampla segundo a qual o intelecto finito não compreende a natureza perfeita (infinita) de Deus. Descartes distingue conceber e compreender de conhecer e admite que, embora o intelecto finito não conceba pela imaginação a natureza de Deus, tampouco a compreenda, no sentido de que não pode abarcar as infinitas propriedades infinitas de Deus, o intelecto finito pode conhecer a natureza de Deus. Isso parece ser o que Descartes quer dizer quando afirma em carta a Mersenne:" "Digo que sei [...] e não que o concebo ou o compreendo, pois se pode saber que Deus é infinito e onipotente ainda que nossa alma, sendo finita, não o possa compreender [...] pois compreender é abraçar com o pensamento, mas, para saber uma coisa, basta tocá-la com o pensamento" (AT I, p. 152). O intelecto finito não compreende a natureza de Deus por duas razões: o intelecto finito não é capaz de enumerar as infinitas propriedades de Deus e não é capaz de abarcar o grau infinito dessas propriedades, como diz Descartes a Burman, "não concebemos [as perfeições e atributos de Deus], ou antes, para concebê-las, as concebemos como indefinidas" (AT V, p. 154). Mas, se é assim, parece que, porque o intelecto finito não compreende a infinitude dos atributos divinos, não pode compreender como é possível que Deus crie o que a esse intelecto finito parece impossível.

Até aqui, entretanto, como vimos, só se pode afirmar que Deus poderia estar ou não sujeito aos princípios lógicos desde a eternidade ao criar. Deus cria os princípios lógicos na mente finita, mas nada impede que ele os tenha seguido em seu ato criador. Nada impede e tampouco nada o obriga a usá-los.

9 Carta de 5 de fevereiro de 1649.

10 Carta de 15 de abril de 1630.

11 Carta de 2 de maio de 1644.

12 Carta de 27 de maio de 1630. 
Entretanto, se atentarmos para o que conhecemos da natureza de Deus, somos levados a afirmar que Descartes tem que admitir a tese mais forte segundo a qual Deus não pode estar sujeito aos princípios lógicos. E isso por duas razões. A primeira razão: sabemos que Deus é infinito, como diz Descartes em carta a Elizabeth: ${ }^{13}$ " [...] basta que eu entenda o fato de que Deus não é compreendido por mim para que eu entenda Deus em toda sua verdade e como ele é, desde que eu também julgue que há nele todas as perfeições que eu entendo claramente, e muitas outras que não percebo" (AT V, p. 359); e, se sabemos que a natureza de Deus é perfeita, infinita, sabemos que não há em Deus nenhum tipo de limitação. Como ele diz em suas respostas às objeções de Caterus acerca do infinito, "[...] podemos clara e distintamente conceber que algo é de tal maneira que não há nele qualquer limitação, o que consiste em entender claramente que isso é infinito" (AT VII, p. 12). A ausência de quaisquer limites em Deus é afirmada também nos "Princípios", ${ }^{14}$ quando Descartes distingue o que é indefinido, a saber, "todas as coisas em que não podemos, de algum ponto de vista, encontrar um limite" do que é infinito, a saber, Deus "pois é só nele que, sob todos os aspectos, não apenas não reconhecemos limite algum, mas também entendemos positivamente que não há nenhum" (AT VIIIA, p. 15; ênfase acrescentada). Ora, se Deus é infinito no sentido em que não tem limite algum sob nenhum aspecto, e se a estrutura lógica é uma limitação da mente finita criada, então Deus não só pode não estar sujeito aos princípios lógicos, mas necessariamente não está. Assim, admitindo que os princípios lógicos são criados por Deus como limitação da estrutura do intelecto finito de tal modo que esse conceba coisas como possíveis ou impossíveis, e dada a infinitude das infinitas propriedades de Deus, é necessário que, segundo Descartes, Deus não esteja submetido ao princípios lógicos. Que ao intelecto finito mas não à criação de Deus se aplica o conceito de contraditoriedade parece claro, por exemplo, em carta a Elizabeth, ${ }^{15}$ onde Descartes pretende explicar as teses da distinção real e da união entre corpo e alma. Nessa carta, Descartes sugere que ao menos uma das criações de Deus aparece à mente finita como contraditória com relação a uma outra, e por essa razão não pode ser concebida clara e distintamente pelo intelecto finito: "[...] não me parece que o espírito humano seja capaz de conceber bem distintamente e ao mesmo tempo, a distinção entre corpo e alma e a sua união [...]" (AT III, p. 693). Uma outra indicação de que, segundo Descartes, o conceito de contraditoriedade é aplicável apenas 
ao intelecto finito, mas não a Deus e não necessariamente ao modo como as coisas são, encontra-se nos "Princípios", ${ }^{16}$ quando, ao introduzir a questão da possível compatibilidade entre a tese da preordenação divina e a tese da liberdade humana, Descartes afirma que “[...] podemos nos enredar a nós mesmos em grandes dificuldades se tentarmos conciliar essa pré-ordenação de Deus com a liberdade do nosso arbítrio, e compreender simultaneamente uma e outra" (AT VIIIA, p. 20).

A segunda razão que nos leva a afirmar que, no sistema cartesiano, Deus não pode estar sujeito a princípios lógicos ao criar tem como base o que, segundo Descartes, conhecemos acerca dos atributos de Deus. Na Terceira Meditação, Descartes diz: "[...] a unidade, a simplicidade ou a inseparabilidade de todas as coisas que existem em Deus é uma das principais perfeições que concebo existentes nele" (AT VII, p. 51). ${ }^{17}$ Note-se que, além de afirmar a simplicidade e unidade de Deus, Descartes, nessa passagem, claramente admite que diferentes coisas (no plural) existem em Deus, embora de modo inseparável. Isto é, Descartes não parece estar defendendo a tese de que não há nenhum tipo de distinção em Deus. Se, por um lado, a tese da simplicidade e unidade de Deus leva à inseparabilidade de suas propriedades, por outro, parece permitir que de algum modo se possa distinguir essas propriedades. Descartes parece querer afirmar que não há uma distinção real ou modal entre as diferentes propriedades que percebemos em Deus, mas que podemos distingui-las mentalmente, isto é, conceitualmente. Segundo a explicação dada por Descartes em "Princípios", uma distinção real ocorre entre dois entes que podem existir separadamente (como duas substâncias finitas). A distinção modal, por sua vez, também supõe separabilidade: trata-se da distinção entre uma substância e seus modos ou da distinção entre os diferentes modos de uma substância. Tanto a substância é separável de seus modos como os modos de uma substância são separáveis entre eles. Os modos, entretanto, não podem existir sem a substância, e, por isso, entre os modos e a substância e entre os diferentes modos de uma mesma substância, não há uma distinção real, e sim uma distinção modal. E, finalmente, a distinção conceitual, ou de razão, é aquela cuja ideia básica é a de que podemos usar e usamos diferentes conceitos para referir-nos a coisas essencialmente conectadas (ou inseparáveis) ou a uma única coisa. ${ }^{18}$ Se Deus é uno e nele as propriedades não se separam,

16 "Princípios" I, p. 41.

17 As citações de passagens das "Meditações Metafísicas" serão extraídas da tradução de Bento Prado Junior e J. Guinsburg, Coleção Os Pensadores XV (Editora Abril Cultural, 1973).

18 Veja-se "Princípios", Parte I, artigos 60-62 (AT VIIIA, p. 29-30). 
mas ainda assim podemos falar de suas diferentes propriedades, é porque há uma distinção nem real nem modal, mas sim de razão que nos permite por diferentes termos referirmo-nos a uma única coisa. Deus, embora simples, pode ser concebido de diversas maneiras

Assim, é em virtude da simplicidade e unicidade de Deus que, segundo Descartes, em Deus as faculdades da vontade e do entendimento não se distinguem realmente nem modalmente, como fica claro em sua carta a Mesland: 19 “[...] porque em Deus ver e querer são uma única e mesma coisa" (AT IV, p. 119). Mais ainda, porque Deus é perfeito, Deus é indivisível e nada nele é em potência: Deus é puro único ato e, na medida em que não é divisível como a matéria, é ato puramente intelectual. Como diz Descartes, "Deus é puro intelecto" (AT X, p. 218), isto é, é puro pensar. Ainda em virtude da simplicidade de Deus, nele pensar, querer e criar são um único ato, que é o que Descartes afirma, por exemplo, nos "Princípios": 20 "Deus [...] por um único e sempre o mesmo e simplicíssimo ato, simultaneamente entende, quer e opera tudo" (AT VIIIA, p. 14). Assim, com base nos atributos que conhecemos de Deus, podemos afirmar que: (1) Os atributos de Deus são idênticos uns aos outros; (2) Deus é infinito e puro pensamento em ato; (3) age por um ato único simples e eterno; e (4) Deus é idêntico a cada um de seus atributos. ${ }^{21}$ Deus ao pensar, quer e cria.

Um outro atributo de Deus que Descartes admite conhecermos é sua onisciência, como é claro, por exemplo, na Quarta Meditação: “[...] se considero a faculdade de conceber que há em mim [...] [e], da mesma maneira, se examino a memória ou a imaginação, ou qualquer outro poder, não encontro nenhum [...] que em Deus não seja imenso e infinito" (AT VII, p. 57). Em virtude da onisciência de Deus, pode-se afirmar que Deus pensa em todas as coisas. Mas, se pensar, querer e criar são um único ato, ao pensar em todas as coisas Deus quer e cria todas as coisas. Deus é, por isso mesmo, onipotente e criador de todas as coisas. A questão então passa a ser o que significa dizer que Deus pensa todas as coisas. Se "pensar todas as coisas" nesse contexto significa que Deus pensa em tudo o que a mente finita estruturada por princípios lógicos pensa e apenas nisso, teríamos que admitir que Deus necessariamente está sujeito aos princípios lógicos, pois o que para nós é possível é o que é pensável segundo a constituição de nossa

19 Carta de 2 de maio de 1644.

20 "Princípios", Parte 1, p. 23.

21 Veja-se "Princípios", Parte 1, artigo 23 (AT XVIIIA, p. 14); "Entretien avec Burman" (ATV, p. 166) e carta a Mersenne (AT III, pp. 149-150). 
mente finita. Se Deus pensasse apenas como nós, estaria, como nós, sujeito à constituição finita de nossas mentes. Mas isso, como vimos, iria contra a tese da infinitude de Deus. Se os princípios lógicos são o que tornam finita a mente finita na medida em que estruturam o entendimento finito, então porque Deus é ilimitado em todos os aspectos não pode estar sujeito a estes princípios. Em contrapartida, se admitimos que "pensar tudo" significa "pensar no que ele quer" limitando assim seu pensar pela sua vontade, teríamos que admitir que em Deus a faculdade da vontade não se distingue apenas conceitualmente do intelecto, mas é prioritária com relação a ele, o que contraria a tese da identidade dos atributos. Assim, parece, temos que admitir que Deus "pensar em todas as coisas" significa que ele necessariamente pensa no que para nós é pensável e, portanto, logicamente possível, e no que para nós é impensável, isto é, logicamente impossível. E, mais ainda, se, ao pensar, Deus quer e cria, então Deus pensa, quer e cria o que é pensável pelo intelecto finito e o que não é pensável pelo intelecto finito. Note-se que afirmar que Deus cria o que para nós é inconcebível não é o mesmo que afirmar que sabemos o que é o impensável por nós. O que podemos conceber é que Deus cria aquilo que não podemos conceber, já que passa da fronteira do que é por nós concebível. ${ }^{22}$

Dizer que Deus, porque pensa tudo cria tudo, parece, entretanto, no sistema cartesiano significar apenas que Deus cria todas as essências nele próprio ao criar-se. ${ }^{23}$ Descartes em respostas às objeções de Caterus (AT VII, p. 110)

22 Essa linha interpretativa é sugerida por M. Wilson (1978), quando ela afirma que Descartes assume que a necessidade das verdades necessárias das proposições matemáticas depende da estrutura de nossa mente finita e que a história da epistemologia e da filosofia da matemática demonstram que essa posição não é tão idiossincrática quanto parece à primeira vista. Wilson sugere algo ainda mais forte: com base no que Putnam afirma em "Mind, Language and Reality", diz ela, é possível pensar que o que nos aparece como inconcebível por vezes termine por se mostrar verdadeiro, como seria o caso da cosmologia Rietmanniana (p. 126 e nota 31).

23 H. Frankfurt (1991) situa a tese de Descartes da livre criação das verdades eternas em um contexto de discussão com os escolásticos, para quem haveria dois tipos de essências: essências possíveis que não são criaturas de Deus, mas derivam necessariamente do fato de Deus ser o que é, e essências reais, que seriam as essências dos indivíduos existentes. Estas são criadas quando o indivíduo é criado. A doutrina da criação das verdades eternas diria respeito às essências possíveis, e a tese escolástica seria a de que as verdades eternas não são limitações externas ao poder de Deus, tampouco são criadas por Deus. As verdades eternas, entretanto, dependem de Deus na medida em que derivam da própria essência de Deus e, nesse sentido, só existem porque Deus existe. Assim, ainda segundo Frankfurt, é falsa a afirmação de Descartes de que sua tese da livre criação das verdades eternas seria a única a evitar a afirmação da independência das verdades eternas. Frankfurt admite, entretanto, uma outra explicação para a relevância da tese cartesiana: segundo Descartes, essa explicação escolástica da dependência das verdades eternas indica que estes, violando a tese da simplicidade de Deus, admitem em Deus uma distinção entre entendimento e vontade, o que acarretaria na possibilidade de Deus apenas conceber as essências possíveis, sem criá-las. A tese cartesiana teria o mérito de sustentar a criação dessas verdades por Deus. Dada essa contextualização feita por Frankfurt do problema, neste artigo sustento que Descartes admite que em um único ato as essências possíveis são criadas por Deus (em oposição a emanarem da essência de Deus) quando este, dada sua onipotência, cria a si próprio e quando criadas são (algumas) instanciadas na mente finita e/ou no mundo atual. 
e de Arnauld (AT VII, pp. 231-232) discute sua tese de que Deus é causa de si próprio. Nessas respostas, Descartes deixa claro que Deus é causa de si na medida em que seu imenso poder dispensa qualquer outra causa. E, se é em virtude do poder de Deus que ele não precisa de outra causa para existir, então é em virtude dele próprio que ele não precisa de outra causa para existir e, portanto, é por algo de positivo nele, sua onipotência, que ele existe. Nesse sentido, Deus é causa de si não como causa eficiente: Deus deriva de sua essência sua existência, como uma causa formal: “[...] isto é, por que ele tem o tipo de essência que implica que ele não precisa de uma causa eficiente" (AT VII, p. 238). Assim, Deus, ao ser, pensa e cria a si próprio. Se, como dito acima, Deus é puro pensamento, sua essência constitui-se, por assim dizer, "dos conteúdos de seu pensamento". ${ }^{24}$ Sendo Deus uno, seu ato de pensar e os conteúdos exibidos por esse ato são uma única e mesma coisa. E, se por esse ato de pensar, como vimos, Deus pensa todas as coisas, Deus, ao ser, pensa, quer e estabelece nele próprio as essências de todas as coisas. Isso parece ser confirmado pelo que Descartes diz em sua resposta às Segundas Objeções: "[...] toda operação do intelecto é um ente conceitual, isto é, um ente que tem sua origem no pensamento; e na verdade pode-se dizer que todo o universo é um ente que se origina no pensamento de Deus, isto é, um ente criado por um único ato da mente divina" (AT VII, p. 134).

Deus, pensamento puro, em ato e infinito é essencialmente (ainda que eminentemente $)^{25}$ todas as infinitas coisas enquanto pensadas por ele. Se Deus é puro pensamento infinito, isto é, não submetido aos princípios lógicos, ao ser, Deus pensa e cria em si todas as essências: as essências que nos aparecem como impossíveis por não podermos concebê-las clara e distintamente e as essências que concebemos. Assim, Deus cria em si, pensamento puro em ato e infinito que é, os conteúdos de seu intelecto que são todas as coisas enquanto pensadas e, portanto, enquanto essências. Como diz Descartes em carta a Mersenne:26 "Você pergunta o que Deus fez para produzi-las [as verdades eternas]. Respondo que desde a eternidade ele as quis e as pensou como sendo,

24 Em Deus não há propriamente conteúdos de pensamento, já que Deus não tem partes.

25 Essa leitura se alinha com a de T. Schmaltz (1991) que sustenta que as essências ou as verdades eternas e Deus são uma e a mesma coisa. L. Nolan (1997) rejeita essa leitura de Schmaltz com base em três problemas, dos quais o seguinte me parece o mais grave: essa leitura atribuiria a Descartes a tese herética de que Deus seria idêntico a suas criaturas. Segundo Nolan, Schmaltz, em correspondência, responde a essa objeção recorrendo a uma distinção feita por Descartes em carta a Mersenne, de 27 de maio de 1630, entre causar e criar e afirmando que Deus causa as verdades eternas, mas não as cria, o que evitaria a identificação entre Deus e criaturas. Seguindo essa sugestão de Schmaltz, parece ser possível afirmar que, embora Deus não seja idêntico a sua criação, sua essência imaterial e infinita contém e causa a essência de todas as coisas.

26 Carta de 27 de maio de 1630. 
e exatamente por isso eles as criou. Ou, se você reserva o termo 'criou' para a existência de coisas, então ele as estabeleceu e as fez [illas disposuit \& fecit]" (AT I, pp. 152-153).

$\mathrm{O}$ fato de Deus, por ser pensamento puro em ato e infinito, estabelecer nele próprio as essências de todas as coisas não antecipa ainda a existência nem da contraparte objetiva na mente finita nem da contraparte formal no mundo atual dessas essências. Nesse contexto, pensar não é necessariamente criar nem no mundo objetivo da mente finita nem no mundo atual, mas criar em sua própria mente, isto é, na mente de Deus. Isso significa dizer apenas que Deus, porque cria tudo o que pensa, estabelece nele mesmo tudo, isto é, todas as essências e verdades. E, visto que a mente finita só pode conceber aquilo permitido por sua estrutura lógica, ao criar todas as essências Deus instancia na mente finita apenas aquelas concebíveis por esta, isto é, aquelas que logicamente são possíveis de existir. Assim, o ser objetivo exibido por cada ideia na mente finita é uma instanciação de uma essência pensada e concomitantemente estabelecida por Deus. Toda ideia clara e distinta da mente finita é, portanto, inata na medida em que Deus desde a eternidade nela instancia uma verdade eterna ou uma natureza verdadeira e imutável. Em contrapartida, no que diz respeito ao mundo atual, a mente finita pode afirmar que Deus com certeza instancia essências que a mente finita pode conceber como possíveis. Mas, se Deus pensa nas infinitas coisas e pensa independentemente das limitações lógicas que estruturam a mente finita, então é possível que desde a eternidade, além das coisas que a mente finita pode perceber, Deus tenha instanciado outras coisas as quais a mente finita não pode perceber. Deus em seu único ato puro de pensar existe e assim estabelece as essências em seu intelecto infinito, instanciando no intelecto finito algumas das essências pensadas e estabelecidas por ele (as que são logicamente concebíveis), e cria, instanciando no mundo atual, algumas ou todas as essências pensadas e estabelecidas por ele. $\mathrm{O}$ intelecto finito pode perceber que Deus necessariamente cria todas as essências em seu pensamento (por ser puro ato infinito de pensar), pode perceber que Deus cria instâncias de algumas dessas essências nas mentes finitas (aquelas essências concebíveis por uma mente estruturada segundo os princípios lógicos), pode perceber que Deus cria no mundo atual instâncias das essências pensadas por ele (porque percebe a existência de coisas), mas talvez não possa perceber todas as essências instanciadas no mundo porque não poderia perceber instâncias que não se sujeitam ao aparato lógico.

Afirmar que Deus livremente cria as essências e que estas têm ou não uma contraparte atual não significa que Deus cria as modalidades em termos absolutos, isto é, do ponto de vista de Deus. Deus cria modalidades no intelecto 
finito ao estruturar esse intelecto segundo as leis lógicas: o que é pensável pelo intelecto finito (isto é, as essências nele exibidas) é logicamente possível de existir atualmente. Mas ao criar essências em seu próprio intelecto, isto é, ao pensar, Deus não cria possibilidades. Ele cria as coisas como são: existindo em seu intelecto (nele mesmo, que é puro intelecto), algumas existindo também objetivamente no intelecto finito, e algumas (ou todas) existindo, além disso, também atualmente. Isto é, Deus pensa essências como tendo uma contraparte existente na mente finita e essências como tendo contraparte na mente e no mundo atual existente. Assim, do ponto de vista de Deus nada é possível, as coisas simplesmente são. Ou são apenas pensadas por ele ou são pensadas por ele, pensadas pela mente finita e existentes no mundo atual, ou pensadas por ele, impensáveis pela mente finita e existentes no mundo atual. Isso não implica, portanto, que o Deus cartesiano está diante de um mundo de infinitas possibilidades independentes dele nem mesmo diante de possibilidades dependentes dele. No caso de Deus, pensar é criar essências com ou sem instâncias na mente finita e com ou sem instâncias no mundo atual. Embora não crie a modalidade absoluta, ao criar o intelecto finito estruturado segundo leis lógicas, Deus cria a modalidade para os seres finitos: as essências exibidas no intelecto finito consistem no conteúdo das ideias percebidas clara e distintamente, isto é, o conteúdo das ideias cuja contraparte atual é logicamente possível. E, como vimos, o fato de Deus criar o intelecto finito estruturado a partir de certos princípios e com um determinado sistema conceitual não garante que esse intelecto possa conhecer o que Deus pensa como existente objetiva e formalmente. Deus estabelece o que é pensável por este intelecto finito, mas nem por isso garante que o que é pensável é tudo o que existe atualmente.

A hipótese interpretativa da tese da livre criação das verdades eternas aqui apresentada parece ter que lidar com o embaraço de que talvez o sistema cartesiano tenha que admitir a possibilidade de um mundo atual criado por Deus que não tem sentido para a mente finita, isto é, um mundo ininteligível do ponto de vista do homem. Dada essa hipótese de que Deus necessariamente pensa em todas as essências e verdades, a saber, as concebíveis e as não concebíveis por um intelecto limitado por uma estrutura lógica, e dado ainda que Deus pode tê-las pensado todas como atualmente existentes, talvez seja necessário admitir que no sistema cartesiano Deus, afinal, em um certo sentido, é enganador: estrutura o intelecto humano com faculdades cognitivas (entendimento e vontade) que operam segundo princípios lógicos que, entretanto, talvez impeçam esse intelecto de conhecer o mundo atual. Deus não seria enganador no sentido estrito de instanciar na mente finita ideias 
claras e distintas falsas, mas seria enganador em um outro sentido, a saber, na medida em que, apesar de criar a mente humana aparelhada com princípios lógicos para conhecer, o que parece implicar que o mundo é racionalmente compreensível, Deus pode ter criado coisas no mundo que a mente finita desse modo estruturada por ele não é capaz de conhecer. ${ }^{27}$ Mas, a julgar pelo modo como Descartes preserva a veracidade divina no que se refere aos sentidos, não parece implausível que Deus, ainda que veraz, tenha criado um mundo atual refratário ao intelecto humano. Talvez seja possível compreender esse engano da razão, a partir da explicação de Descartes relativa a um tipo especial de erro oriundo dos sentidos, a saber, o erro que não resulta de alucinação ou de circunstâncias inapropriadas à percepção correta. Na Sexta Meditação, ao examinar por que a natureza do homem (o composto corpo/alma) é falível e enganadora, Descartes admite que Deus poderia tê-la criado de modo a nunca se enganar, mas que isso não contribuiria tão bem para a conservação de seu corpo. Deus cria o composto, o homem, de tal modo que cada movimento no corpo causa uma única sensação, ainda que por vezes essa sensação o engane, porque é essa sensação que na maior parte das vezes é mais apropriada e útil à conservação do corpo. Ao examinar como exemplo o erro do hidrópico, Descartes torna claro que a falibilidade do homem é resultante da bondade divina e consistente com sua veracidade, em virtude de sua utilidade para a preservação e aperfeiçoamento do corpo:

[...] com respeito à totalidade do composto, isto é, do espírito ou da alma unida a este corpo, $[\ldots]$ trata-se de verdadeiro erro da natureza, [...] [o] fato de ter sede, quando lhe é nocivo beber. [...] [N]oto que, de todos os movimentos que se verificam na parte do cérebro do qual o espírito recebe imediatamente a impressão, cada um causa apenas um certo sentimento [...] Deus podia estabelecer a natureza do homem de tal sorte que esse movimento no cérebro fizesse com que o espírito sentisse uma coisa inteiramente diferente [...] mas nada disso teria contribuído tão bem para a conservação do corpo quanto aquilo que lhe faz sentir. [...] [A] natureza do homem,

27 Agradeço ao parecerista anônimo da revista Kriterion por ter chamado minha atenção para o fato de que, nesse caso, trata-se de um engano peculiar com relação ao que seria, segundo uma certa interpretação, o engano considerado na Primeira Meditação por meio da hipótese do Deus Enganador. Deus aqui não seria enganador por sistematicamente enganar quanto à verdade das ideias claras e distintas da mente finita. Seria enganador, entretanto, no sentido de criar uma substância cujas faculdades essenciais são cognitivas e, portanto, no sentido de criar uma substância para conhecer e, ao mesmo tempo, criar um mundo que não é, todo ele, por ela cognoscível. Deus seria, portanto, ainda assim enganador em um certo sentido, a saber, na medida em que trata-se aqui de um erro sistemático relativo à própria natureza da substância pensante na medida em que esta erroneamente opera como se tudo no mundo fosse racionalmente cognoscível. Esse tipo de erro sistemático abalaria a veracidade/bondade divina de modo análogo a como abala o erro relativo aos sentidos que tampouco se refere às ideias claras e distintas da razão. A veracidade/bondade divina fica ameaçada nesses dois tipos de erro na medida em que ambos provêm diretamente da natureza de uma criatura de Deus. 
enquanto composto do espírito e do corpo, não pode deixar de ser, algumas vezes, falível e enganadora (AT VII, pp. 85-86).

A explicação cartesiana do tipo especial de erro dos sentidos e das paixões humanas recorre à bondade divina. Deus em sua suma bondade cria seres (homens) com a capacidade de conservar seu corpo por meio de sensações, ainda que isso implique por vezes em um certo tipo de erro. Mas, se é assim, talvez se possa afirmar que do mesmo modo que, segundo Descartes, Deus cria os sentidos operando como operam no homem porque os sentidos têm uma função essencial para a preservação de seu corpo, Deus cria o intelecto humano operando como opera (segundo os princípios lógicos) também em virtude de uma função essencial, a saber, preservar e aperfeiçoar uma natureza criada por Deus: a alma. Buscar compreender o mundo segundo as leis da racionalidade, isto é, compreender o mundo como tendo sentido, talvez seja o melhor meio para o homem conservar e aperfeiçoar seu intelecto, isto é, suas faculdades cognitivas, ainda que esse mundo atual de fato não tenha exatamente apenas esse sentido.

Assim, dada a tese da livre criação das verdades eternas, podemos afirmar: Deus cria nele próprio todas as essências e todos os princípios e, não estando submetido a esses princípios, necessariamente não cria segundo eles. Deus cria algumas dessas essências e alguns desses princípios como existindo formalmente no mundo e/ou na mente de um intelecto formalmente existente no mundo (intelecto do homem) e outros como existindo apenas nele próprio. Deus cria os princípios lógicos como estruturando o intelecto finito, mas não necessariamente como estruturando o mundo atual. É plausível afirmar que é possível que o intelecto finito não possa conhecer o mundo tal como ele é pensado por Deus. Apesar da veracidade divina, em virtude de sua suma bondade Deus pode ter pensado e criado um mundo atual irracional, ainda que para o intelecto humano o mundo tenha sentido.

\section{Referências}

DESCARTES, R. "Oeuvres de Descartes". C. Adam e P. Tannery (ed.). Paris: Cerf, 1897-1913. (Reeditada Paris: Vrin, 1957. 12 Vol.). "Meditações Metafísicas". Tradução de Bento Prado Junior e J. Guinsburg, Coleção Os Pensadores XV. São Paulo: Abril Cultural, 1973. . "Princípios da Filosofia". Tradução coordenada por Guido A. de Almeida Rio de Janeiro: Ed. UFRJ, 2002. 
FRANKFURT, H. "Descartes on the Creation of the Eternal Truths". In: René Descartes - Critical Assessments. Vol. III. Ed. G. J. D. Moyal. Londres: Routledge, 1991.

ISHIGURO, H. "The Status of Necessity and Impossibility in Descartes". In: Essays on Descartes' Meditations. Ed. A. O. Rorty. 1986.

NOLAN, L. "The Ontological Status of Cartesian Nature". Pacific Philosophical Quarterly, 78, pp. 169-194, 1997.

NORMORE, C. “Descartes's Possibilities”. In: René Descartes-Critical Assessments. Vol. III. Ed. G. J. D. Moyal. Londres: Routledge, 1991.

SCHMALTZ, T. M. "Platonism and Descartes' View of Immutable Essences". Archiv für Geschichte der Philosophie, Vol. 73, Issue 2, pp. 129-170, 2009.

WILSON, M. "Descartes Ego Cogito, Ergo Sum". Ed. T. Honderich. London; New York, Routledge \& Kegan Paul, 1978. 